\title{
Autonomia, paternalismo e dominação na formação das preferências
}

Luis Felipe Miguel

\section{Introdução $^{1}$}

Explicada de maneira esquemática, toda ação política é fruto do encontro entre uma determinada situação social e material, de um lado, e as disposições e a compreensão daquela situação pelos agentes, do outro. O bolchevismo apreendia o modelo ao falar de "condições objetivas" e "condições subjetivas" para a revolução, as primeiras indicando o estágio de evolução do capitalismo e as segundas, o grau de amadurecimento do sujeito coletivo "classe operária". Mas mesmo para ações mais comezinhas e no plano individual, como a decisão de voto, o engajamento em algum tipo de mobilização ou até a manifestação de simpatia por uma causa, esse encontro é essencial para explicar o comportamento político.

Parte da explicação, assim, reside nas disposições dos agentes. Mas elas também precisam ser explicadas. Estão ligadas à avaliação das próprias possibilidades de ação, à noção da identidade individual e dos pertencimentos de grupo e, de forma mais geral, às preferências do agente. Torna-se crucial a questão da formação das preferências, que, no entanto, tende a ser ignorada por grande parte da ciência política, o que é um efeito combinado das influências do liberalismo, do utilitarismo e, por fim, dos modelos da economia neoclássica. As preferências são entendidas como "dados" prévios à política, a serem aceitos como tal, sem questionamento. Elas são vistas como produzidas na esfera privada e, ademais, como derivações de tendências pretensamente naturais (a "maximização da própria utilidade"). A política seria um espaço apenas de agregação dessas preferências prévias. Além disso, os modelos dominantes da ciência política preferem lidar com as escolhas, que tratam como se fossem proxies infalíveis das preferências. A relação entre preferência e escolha é aceita como autoevidente e não

\footnotetext{
${ }^{1}$ Este artigo integra a pesquisa "Teoria democrática, dominação política e desigualdades sociais", apoiada pelo Conselho Nacional de Desenvolvimento Científico e Tecnológico (CNPq) com uma bolsa de Produtividade em Pesquisa. Versões anteriores foram apresentadas no II Colóquio Internacional "Discurso, Teoria e Ação Política", que ocorreu na Universidade Federal do Rio de Janeiro, em setembro de 2012, e no V Congreso de la Asociación Uruguaya de Ciencia Política, realizado em Montevidéu, em outubro de 2014 (agradeço à Capes pelo auxílio que me permitiu dele participar). Também tive oportunidade de discuti-lo na Universidade Estadual de Londrina, em agosto de 2012, e na Universidade de Brasília, em novembro de 2012. Agradeço as críticas, comentários e sugestões dos participantes desses fóruns, em particular Flávia Biroli, Maria Aparecida Abreu e Raquel Kritsch. Agradeço também a leitura prévia e os comentários de Regina Dalcastagnè. E, por fim, aos pareceristas anônimos de Opinião Pública. Permaneço, é claro, único responsável por equívocos e omissões.
} 
problemática. E o processo de produção das preferências está fora do alcance da reflexão teórica.

Neste artigo, argumento que o descuido em relação aos processos de formação das preferências leva a que, na maior parte da teoria política liberal, a discussão sobre as restrições à autonomia dos agentes se concentre no problema do paternalismo. No entanto, a autonomia é constrangida sobretudo pelas relações de dominação, que operam tanto sobre as possibilidades de comportamento efetivo quanto sobre os processos de formação das preferências. Na primeira seção do texto, "O valor da autonomia e a formação das preferências", discuto o valor da autonomia no pensamento liberal - que entendo que é um valor que se mantém, a despeito das críticas às insuficiências do liberalismo como corpo doutrinário - e o relaciono à formação das preferências. Na segunda seção, "Paternalismo e antipaternalismo", reconstruo, em grandes traços, o argumento contra o paternalismo, tal como apresentado a partir de Stuart Mill. A terceira seção, "A dominação em questão", dedica-se a indicar a centralidade do problema da dominação para a discussão em tela. Na breve conclusão, enfim, indico que, embora os problemas vinculados às condições individuais de autonomia não possam ser deixados de lado, tampouco é possível se limitar a eles. Para o funcionamento da democracia política, são igualmente relevantes as questões vinculadas às assimetrias entre grupos, isto é, às desigualdades nas possibilidades de formulação das preferências coletivas.

\section{O valor da autonomia e a formação das preferências}

A ideia de um indivíduo autônomo, capaz de decidir sua vida por sua própria conta, é central para o pensamento liberal. Ao utilizar a expressão "pensamento liberal" estou unificando, sob um rótulo abrangente e em favor da simplicidade de exposição, uma multiplicidade de posições, com profundo debate interno sobre inúmeras questões, inclusive a que me mobiliza neste artigo. Mas é inegável que o tronco central do liberalismo clássico, formado do século XVII ao XIX, pressupõe a agência individual autônoma. De Locke, Smith e Constant a Stuart Mill e Tocqueville, há uma percepção constante nessa direção. No século XX, o debate se expande. A vertente ultraliberal, de Hayek a Nozick, permanece vinculada a uma visão bastante plana da autonomia individual, que, no entanto, é desafiada por algumas compreensões mais sofisticadas.

Tais compreensões podem ser agrupadas nas duas tendências identificadas por Nussbaum (2011). De um lado, o liberalismo "perfeccionista" de Isaiah Berlin ou Joseph Raz, que apresenta a ampliação da autonomia individual como sua missão. Do outro, um liberalismo "político", que se coloca contra a tradição dominante da corrente ao rejeitar a centralidade do valor da autonomia. Tal valor não se acomodaria a algumas opções individuais (por exemplo, seguir uma religião autoritária) e, portanto, violaria a noção de neutralidade em relação às diferentes concepções de bem, que passa a ocupar a posição 
central nessa compreensão do liberalismo. Segundo Nussbaum, essa seria a posição de John Rawls e dela própria. Mas há uma contradição, que aliás ela mesma assinala: a opção por qualquer modo de vida é legítima desde que seja fruto da livre escolha do indivíduo. O fiel da religião autoritária de Nussbaum é, assim, também um agente autônomo, que decide abdicar de sua autonomia; não está longe da ideia de liberdade para vender a si mesmo como escravo, de que falava Nozick (1974, p. 331). E se a adesão a tal seita é a única opção que possui, a legitimidade de sua escolha fica invalidada.

Assim, o liberalismo - seja ele ultra, perfeccionista ou político - tende a gravitar em torno das noções de autonomia individual e de pluralismo de alternativas, com suas eventuais divergências dizendo respeito muito mais a como os dois termos da equação se combinam. Em suas franjas mais igualitárias, como em Rawls, Barry ou Dworkin, emerge uma preocupação com as condições efetivas de escolha, que se radicaliza na defesa da renda básica universal por Van Parijs (1991, 1992). Mas tal ampliação do elenco de alternativas exequíveis, graças à melhoria das condições materiais, aparece sempre em primeiro lugar como a ampliação da possibilidade de consecução de preferências preexistentes.

O sujeito autônomo é aquele que determina seu comportamento, que assume a responsabilidade moral por suas escolhas e que, nessas escolhas, se guia por critérios que ele mesmo produz ou aos quais adere voluntariamente ${ }^{2}$. Na definição, é importante levar em conta os dois passos: as escolhas e aquilo que as informa. A redução da autonomia à possibilidade de livre escolha, como por vezes ocorre - numa longa linhagem que vai de Hayek (1990) e Nozick (1974) a Sunstein (2014, cap. 4) -, impede o aprofundamento da discussão ${ }^{3}$.

Mas escolhas são fruto da interação de preferências com contextos e, por si sós, pouco dizem das motivações dos agentes. Por exemplo: diante da opção entre $A$ e $B$, eu escolho $A$, não porque prefira $A$ - posso ser indiferente ou mesmo preferir $B$-, mas porque, no contexto em que minha decisão é tomada, a escolha de $A$ projeta diante dos outros (ou de mim mesmo) uma determinada imagem. Assim, o que eu prefiro não é A nem $B$, mas essa imagem; e a escolha, em si mesma, não revela minha preferência, a menos que outros elementos sejam acrescentados ao cenário.

É possível, então, entender preferência como a predileção por alguma situação ou estado, que leva ao interesse em determinadas medidas e a escolhas em situações concretas $^{4}$. Minha preferência por tempo livre me leva a ter interesse na redução da

\footnotetext{
2 Para uma breve discussão sobre o conceito de autonomia, ver Biroli (2013, cap. 1).

${ }^{3}$ Cabe anotar que a posição de Sunstein (2014) não corresponde à de Sunstein (1997), representando um recuo em relação à afirmação radical, anterior, da necessidade de produção autônoma de preferências. As divergências entre as duas obras ficarão claras no decorrer deste artigo.

${ }^{4}$ Não julgo que seja particularmente útil a distinção adicional, proposta por Jon Elster, entre preferências e motivações, tampouco sua busca pelos "mecanismos geradores" de ambas, que ele julga que um dia serão decifrados pela neurobiologia e que, por enquanto, resume a dois principais: a busca pela consonância
} 
jornada de trabalho e, assim, orienta escolhas políticas. O interesse se estabelece como o móvel privilegiado do conflito político porque organiza as escolhas e porque as desavenças se ligam a medidas que podem ou não ser efetivadas, não a predileções abstratas (cf. Sunstein, 1997; Miguel, 2014). No restante desta discussão, vou opor a escolha, como momento mais imediato e contextual, ao polo preferência/interesse, revelador de motivações mais profundas.

O exercício da autonomia requer um espaço de liberdade pessoal e justifica a necessidade da vigência dos direitos e garantias liberais. Mas exige também que haja um espectro minimamente robusto de escolhas à disposição dos agentes. Em situações de privação material ou de expectativas sociais opressoras, a autonomia está limitada, mesmo que tecnicamente os agentes possuam liberdade diante das escolhas que lhes são oferecidas. Como dizem as críticas socialista e feminista, trabalhadores que "escolhem" vender sua força de trabalho numa sociedade capitalista ou mulheres que "escolhem" o casamento numa sociedade marcada pela dominação masculina não estão agindo de maneira efetivamente autônoma.

A própria literatura da escolha racional, nos seus ramos mais interessantes, vai além das simples escolhas e trabalha com a relação cruzada entre preferências e circunstâncias. Jon Elster, em particular, analisou como as circunstâncias alteram as nossas preferências e como as preferências também são capazes de nos fazer agir para alterar as circunstâncias. O primeiro caso é emblematizado pela fábula da raposa e das uvas: ao perceber que não conseguia alcançar os frutos, a raposa modificou sua preferência, desprezando-as porque estariam verdes (Elster, 1983) ${ }^{5}$. O segundo caso é ilustrado na Odisseia, quando Ulisses, para poder ouvir o canto das sereias sem se afogar, ordena que seus marujos o amarrem no mastro. Ele reduziu suas alternativas para poder efetivar sua preferência (Elster, 1989; cf. também Elster, 2009b).

Podemos dizer que tais críticas se endereçam às restrições externas ao exercício da autonomia. A modificação das preferências (ou das circunstâncias) toma a feição de uma decisão, consciente ou não, que revela a metapreferência de reduzir a frustração ou de controlar as consequências de médio e longo prazos das ações. No entanto, é possível avançar em outro nível de questionamento - como, aliás, o marxismo e o feminismo fazem. Torna-se necessário investigar até que ponto as preferências que governam as escolhas dos agentes são, elas mesmas, produzidas de forma autônoma.

Para parte do pensamento liberal, sobretudo o mais influenciado pelas doutrinas

cognitiva e o amor-próprio (Elster, 2009a). É um tipo de raciocínio especulativo, fortemente abstrato e generalizante, curioso em si mesmo, mas que obscurece os determinantes concretos da produção das preferências (ou das motivações) dos agentes situados social e historicamente.

5 Bourdieu distingue entre "gostos de luxo (ou de liberdade)" e "gostos de necessidade". Os primeiros são próprios dos indivíduos cujas condições de vida se caracterizam pela distância da necessidade. Os segundos exprimem o ajustamento às necessidades - são os gostos da raposa (Bourdieu, 1979, p. 198). Em vez de focar a opção individual particular, como fazem a fábula e Elster, ele dirige sua atenção às condições sociais. 
utilitaristas, tal questão não se coloca ${ }^{6}$. O utilitarismo pressupõe um interesse universal e espontâneo (a maximização da utilidade), que é comum e uniforme em todos os indivíduos e que, portanto, não é objeto de investigação. Mas é possível deixar a produção das preferências numa caixa-preta, inacessível ao escrutínio dos outros, mesmo sem admitir tal pressuposto. Como dizia Robert Dahl, seria necessário postular, como uma "premissa metodológica", que as pessoas possuem um "entendimento esclarecido dos seus próprios interesses" (Dahl, 1989, p. 182). Trata-se de uma "regra de prudência" que visa evitar o paternalismo, a noção de que alguém, com discernimento superior, pode nos tutelar com vistas (pretensamente) a nosso próprio bem. A adesão à divisa utilitarista (cada um é o melhor juiz de seus próprios interesses) prescinde, assim, de uma adesão completa à visão antropológica do utilitarismo.

O autoritarismo paternalista pode ser detectado em muitas das justificações para regimes ditatoriais. O "autoritarismo instrumental" que caracterizou boa parte do pensamento político brasileiro do século XX (cf. Santos, 1978) é um exemplo: a imaturidade do povo brasileiro exigia soluções autoritárias que o protegessem de si mesmo e que propiciassem sua evolução até um momento indeterminado em que seria capaz de se autogovernar. Outro exemplo são as justificativas para o colonialismo europeu, em discursos que incluem tanto o "fardo do homem branco" de Kipling quanto os "povos crianças" de Taine ou Stuart Mill. Por outro lado, nas nossas ações cotidianas muitas vezes a posição de princípio antipaternalista encontra seus limites, na medida em que justificamos ações que impeçam determinadas pessoas de colocar em risco sua integridade física (viciados em drogas, suicidas etc.).

O componente autoritário do paternalismo fica evidente numa defesa contemporânea de sua aplicação estendida, pela filósofa estadunidense Sarah Conly. A autonomia, diz ela, leva a escolhas piores: "A verdade é que nós não raciocinamos muito bem e em muitos casos não há justificativa para nos deixar lutar com nossas próprias inaptidões e sofrer as consequências" (Conly, 2013, p. 1). Um tipo de paternalismo coercitivo garantiria que as pessoas fariam o que é melhor para elas, mesmo contra sua vontade. No entanto, aquilo que é "o melhor" não é posto em questão - ou seja, a formação das preferências continua não sendo levada em conta. Apenas se substitui o subjetivismo extremo da defesa liberal da autonomia por um objetivismo também extremo, em que certo e errado são definidos de antemão, em geral por meio do apelo a um vago consenso social. Mas quando a autora sustenta que o cigarro deve ser proibido e as bebidas alcoólicas não, baseando-se em que "eu penso que os benefícios do álcool sobrepujam seus riscos" (Conly, 2013, p. 149), fica evidente que a autonomia decisória

\footnotetext{
${ }^{6}$ Uma vertente alternativa, a partir de Kant, mas também de Rousseau, vê a liberdade de fazer o que se bem entende como uma falsa liberdade - uma escravidão diante dos estímulos exteriores. A verdadeira autonomia seria a obediência a normas de conduta autoimpostas. É uma evolução da concepção clássica de que o agente verdadeiramente livre segue a razão, não as paixões. Vou me referir apenas en passant a tal concepção.
} 
se impõe como valor exatamente porque os parâmetros de apreciação não são objetivos ou aceitos de forma unânime.

Passando para um maior grau de abstração filosófica, o antipaternalismo assume a forma da neutralidade em relação às diferentes concepções do bem. A partir pelo menos da teoria da justiça de Rawls (1971), a aceitação dessa neutralidade é praticamente uma linha divisória, que separa o liberalismo de seus críticos. Mas há um passo importante, que vai da afirmação da neutralidade estatal (o Estado não pode privilegiar a realização de uma concepção do bem em relação a outras) à noção de que o processo de produção dessas concepções, pelos indivíduos, está além do nosso escrutínio crítico. A primeira afirmação (a neutralidade do Estado) é merecedora de atenção, ainda que possa ser questionada. A segunda é que vai ao encontro da despreocupação com a formação das preferências, retirando do nosso campo de visão um elemento crucial da vida política.

Uma das principais frentes de críticas a Rawls dirigiu-se exatamente à sua noção de indivíduo "desencaixado" do ambiente social em que vive (Sandel, 1998). Em que pesem as diferenças entre si, os chamados "comunitaristas" compartilham a repulsa à concepção rawlsiana do self, que ignoraria o caráter constitutivo dos laços associativos mesmo aqueles mais simpáticos à plataforma liberal insistem nesse ponto (Walzer, 1990). Suas objeções, porém, com frequência se ligam à defesa da vinculação a uma "ordem maior", necessária para dotar de sentido a vida de cada pessoa e ameaçada pelo individualismo hoje dominante (Taylor, 2011). Criticando o valor da autonomia liberal, por assumir que ele introduz a ideia de que devemos pairar num vácuo societário, tais autores têm como ambição limitar o horizonte normativo da autonomia, não aprofundar o entendimento dos obstáculos à sua efetivação.

Há também correntes feministas de corte "maternalista" ou então neodurkheimiano, que denunciam o "mito da autonomia" e pedem que enfatizemos a nossa "interdependência" (Fineman, 2005). Essas críticas denotam uma confusão entre autonomia e egoísmo, ausência de ligações com outras pessoas, ausência de socialização; e também falta de espaço para entender a relação, que é complexa, entre autonomia pessoal e autonomia coletiva.

É possível apagar a ideia de autonomia individual, como faz o Rousseau do Contrato (Rousseau, 1964). Como a vontade geral emana (também) de mim, ao me curvar a ela eu me curvo a mim mesmo e sou mais livre nessa obediência do que na liberdade - já que, como Rousseau diz na "Profissão de fé do vigário saboiano", nisso antecipando Kant, fazer a cada momento o que quero é entregar-me às tentações e, assim, tornar-me escravo delas (Rousseau, 1992). E, no outro polo, é possível apagar a ideia de autonomia coletiva, abraçando radicalmente a noção de que temos uns com os outros relações exclusivamente instrumentais e que as regras de convívio são simplesmente arranjos racionais para preservar, com segurança, a esfera de autonomia privada, uma longa tradição que vai de Hobbes a Nozick (e além). 
É mais interessante, porém, preservar os dois valores e a tensão entre eles - que é a tensão entre democracia e liberalismo. Não podemos abrir mão nem de um nem de outro, mas também estamos escolados demais para aceitar a ilusão de que eles vão necessariamente se harmonizar. É necessário que as pessoas produzam juntas, da forma mais igualitária, as regras que regem a vida social. E é necessário que cada um tenha condições de decidir sobre sua própria vida. As fronteiras entre uma coisa e outra não são e não serão claras; conciliá-las é uma tarefa sempre presente e nunca concluída.

De fato, os indivíduos, por mais autônomos que possam ser concebidos, não estabelecem suas preferências num vácuo afetivo. Se o critério de autonomia é que as preferências não sofram qualquer influência, brotando de um eu essencial, então nenhuma autonomia é possível, até porque tal eu não existe. Como mostrou Pierre Bourdieu, em obra já clássica, as opções pessoais são efeitos de matrizes de disposições socialmente disseminadas e só são compreensíveis dentro das relações objetivas entre diferentes posições no mundo social. Mas não se trata de denunciar distorções na manifestação de um pretenso eu autêntico, ponto fixo que deveria dotar de sentido todas as múltiplas escolhas individuais e que, quando não se manifesta plenamente, é por obra de uma intervenção indevida. Tal ponto de fato não existe. A questão é entender o processo de constituição social das individualidades (Bourdieu, 1979).

O que está em jogo, portanto, é entender que há constrangimentos e incentivos incidindo assimetricamente sobre os integrantes dos diferentes grupos sociais, gerando diferentes formas de ajuste das preferências. Assim, não são apenas as restrições externas à autonomia que espelham a desigualdade social, mas também os processos de produção das preferências. Se nenhuma preferência brota no vazio dos laços sociais, algumas são menos livremente projetadas do que outras.

Descartada a ideia de uma sociedade de indivíduos atomizados e reconhecida a inevitabilidade da influência do ambiente social, o sentido normativo da autonomia precisa ser redefinido. É possível dizer que a autonomia exige o preenchimento de três condições: 1) acesso a uma pluralidade de informações e visões de mundo; 2) ausência de custos excessivos e desproporcionais vinculados à adoção de preferências diferentes; e, como corolário, 3) a capacidade de escrutínio crítico sobre as próprias preferências. Não tenho como deixar de herdar valores e visões de mundo do ambiente em que nasci e cresci. Mas posso ter as ferramentas para lê-los de forma mais crítica e, portanto, modificar-me enquanto modifico minha adesão a eles - ou posso não ter essas ferramentas.

Tudo isso torna bastante complexa a tarefa de incluir os processos de formação de preferências na nossa reflexão sobre o agir autônomo. Para tratar um pouco dessas complexidades (e também introduzir outras), introduzo um caso concreto. Pensemos em Lionel Messi, o jogador de futebol argentino, goleador do Futbol Club Barcelona. Até que ponto a trajetória de Messi pode ser vista como fruto de preferências autônomas? Seria possível que, em vez de futebolista milionário, ele optasse por ser um monge budista? 
Um neurocirurgião? Um cobrador de ônibus? Ou um acadêmico de ciência política?

Numa narrativa convencional, as escolhas de Messi são derivadas de seu talento. Segundo as biografias disponíveis, ele se destacava como jogador desde os 5 anos de idade $^{7}$. O talento certamente estimula muitas opções. Preferimos exercer atividades em que temos desempenho bom ou pelo menos razoável, em vez daquelas em que fracassamos impiedosamente. É possível interpretar tal tendência como uma proteção contra a frustração. Mas o "talento" não é um dom natural, e sim uma competência produzida e valorizada socialmente. Se o esporte chamado futebol não tivesse sido criado no século XIX, Messi não teria talento. Se o futebol não fosse um esporte popular na Argentina, Messi não teria talento. Se não fosse um esporte institucionalizado, Messi não teria talento. Ele poderia ser muito bom no jogo das bolas de gude, mas isso não seria reconhecido com um "talento" relevante para suas escolhas de vida.

Podemos acrescentar agora um elemento adicional, de extrema importância: Messi veio de uma família de poucos recursos. É fácil entender, com isso, que o futebol era a grande esperança de mobilidade social para ele e para a família. Um Messi igualmente talentoso, em outro ambiente social, teria pais que hesitariam em abandonar carreiras e profissões para apostar no futuro do filho futebolista. O próprio garoto teria, como horizontes alternativos ao futebol, carreiras como engenheiro, médico, economista. Se subíssemos ainda mais na pirâmide social, ele talvez optasse pela posição de playboy herdeiro, mais tarde capitão de indústria, em vez de goleador. Mas não, a família Messi era relativamente pobre. Por isso, quando ele tinha 13 anos, a família aceitou a proposta do Barcelona e se mudou para a Espanha. Lá, o adolescente Lionel foi bombardeado com hormônios de crescimento, já que ele era baixo para os padrões do futebol moderno e fora diagnosticado com um problema que reduzia sua estatura. Imagino que o tratamento contou com a anuência dele. Mas será que, nessas circunstâncias, o garoto teria condições de dizer: "Não, eu prefiro ser baixinho. Não quero ser jogador de futebol, quero ser jóquei"? Ele teria condições de preferir isso? ${ }^{8}$

A produção das preferências é influenciada por "disposições ou talentos naturais", circunstâncias socioeconômicas, pressão do ambiente e o peso de investimentos prévios, sem falar no valor atribuído à fama e à riqueza. É difícil estabelecer o espaço de autonomia individual nesse processo. Mas é pouco razoável entender o paternalismo como principal obstáculo a ela.

\footnotetext{
${ }^{7}$ Os dados aqui apresentados foram extraídos das seguintes páginas da internet: <http://en.wikipedia.org/wiki/Lionel_Messi>;<http://es.wikipedia.org/wiki/Lionel_Messi>; e <http://www.biografiasyvidas.com/biografia/m/messi.htm>. Acessos em: 15 jun. 2014.

${ }^{8}$ As mesmas questões poderiam ser aplicadas a Lucien Fleurier, protagonista da novela L'enfance d'un chef, de Jean-Paul Sartre (1972). Ele aparece como encarnação da mauvaise foi, mas sua trajetória pode ser interpretada, sem recurso ao existencialismo sartreano, como exemplo da produção social dos valores e das preferências.
} 


\section{Paternalismo e antipaternalismo}

A fonte do rechaço liberal ao paternalismo é indicada sempre - e por bons motivos - como sendo John Stuart Mill (1991). Em Sobre a liberdade, ele argumenta que as pessoas devem ter liberdade para definir seu próprio comportamento, mesmo quando, no olhar de outros, eles estejam prejudicando a si mesmos. Sustentam tal posição argumentos relacionados à incerteza sobre a verdade, ao caráter educativo do erro e ao privilégio epistêmico do indivíduo, o único capaz de aferir de forma segura seu próprio bem-estar.

$O$ veto ao paternalismo impede o recurso à coerção física, à mentira e à manipulação no sentido de modificar comportamentos e/ou preferências dos agentes. Em versões ainda mais exigentes, mesmo a tentativa de persuasão com base na apresentação de informações verídicas e argumentos racionais pode ser objetada, se ela inclui ausência ou diminuição do respeito à autonomia pessoal de quem é seu alvo (Tsai, 2014).

Há dois tipos principais de exceção à aplicação da regra. A primeira é que ela só se aplica aos adultos, já que as crianças seriam, por definição, incapazes de exercer a autonomia. O paternalismo, enquanto tal, consiste exatamente na ação dos pais para tomar as decisões em nome dos filhos e, assim, protegê-los de sua própria racionalidade deficiente. A posição antipaternalista engloba, dessa forma, a noção de que é necessário presumir que todos os adultos são mais ou menos equivalentes no uso da razão. No próprio Stuart Mill, a defesa do colonialismo, em contradição gritante com sua doutrina da liberdade individual, vinculava-se à descrição dos povos não europeus como insuficientemente preparados para o pensamento racional (cf. Mill, 1995, p. 53). Seriam, em suma, "povos crianças", como definiu, quase na mesma época, Hippolyte Taine (1876).

Essa primeira exceção é considerada banal, pelo próprio Stuart Mill e pela maior parte da literatura. A segunda, ao contrário, é muito discutida: há direito de intervir na decisão individual quando ela causa dano a outras pessoas. No entanto, tal dano deve ser definido com clareza: não é admissível restringir a liberdade de alguém porque ela estaria dilapidando talentos potencialmente úteis a outros ou dando maus exemplos. Além disso, o dano deve ser material; um dos principais esforços de Stuart Mill, em Sobre a liberdade, é impugnar o argumento da angústia moral, pelo qual opiniões consideradas ofensivas seriam proibidas de ser expressas, para impedir o sofrimento de quem delas discorda. Caso contrário, os dogmas religiosos, por exemplo, seriam intocáveis. A noção contemporânea de discurso de ódio, como limite válido - talvez o único - à liberdade de expressão, se esforça exatamente por mostrar a vinculação entre a fala e o dano material que ela incita? .

\footnotetext{
${ }^{9}$ Mas as reações ao atentado contra o jornal humorístico francês Charlie Hebdo, em janeiro de 2015,
} 
Os estudos sobre o paternalismo vão diferenciar as maneiras pelas quais ele se apresenta - se é dirigido aos fins ou aos meios, por exemplo. Aqui, é mais importante distinguir os agentes envolvidos nessa relação. Há, como visto, um paternalismo considerado legítimo, quando seu alvo são pessoas desprovidas da capacidade de tomar suas próprias decisões. É o caso de crianças, mas também de adultos com determinados problemas psiquiátricos ou sob efeito de drogas. Ainda assim, restam questões de difícil solução. As fronteiras nem sempre são claras: a tutela sobre as mulheres ou sobre os povos ditos "primitivos" se apoiava exatamente na presunção de sua racionalidade limitada. Hoje, grupos de pessoas com autismo reivindicam o direito de expressar seus próprios interesses, recusando a ideia de que seus pais e familiares seriam mais capazes de protegê-los (Ortega, 2008, 2009).

Além disso, as decisões tomadas de forma paternalista se estendem muito além da infância, moldando o comportamento ulterior dos indivíduos e, assim, incidindo sobre as decisões que tomarão quando já estiverem credenciados à autonomia. É fácil consentir na necessidade que crianças têm de educação, alimentação saudável e proteção contra riscos, três campos em que o paternalismo se exerce. Mas o que dizer, por exemplo, da vinculação a uma crença religiosa? Em sua defesa do ateísmo, o cientista Richard Dawkins marcava como absurdo que crianças fossem rotuladas pelo pertencimento religioso dos pais (Dawkins, 2007, p. 429-433). Trata-se, no entanto, de uma consequência previsível do paternalismo estendido presente na doutrina do pátrio poder (e da correspondente negligência em relação aos direitos das crianças).

São mais controversas as expressões de paternalismo que incidem sobre adultos que se presume que devam agir de forma autônoma. É possível distingui-los de acordo com o agente do paternalismo. Há uma forma de paternalismo identificada em relações interpessoais horizontais - por exemplo, entre amigos. Se alguém extravia um maço de cigarros, a fim de impedir um amigo de fumar, está cerceando sua autonomia decisória, com o objetivo de protegê-lo dos danos que esse hábito pode causar. Ainda que situações desse tipo sejam discutidas com frequência na literatura e, por vezes, apresentadas como ilustrações da negação do reconhecimento do outro como sujeito moral, também é possível pensar que elas são próprias de relações em que há afeto e cuidado mútuo envolvidos, em que o bem-estar alheio é incorporado na compreensão do próprio bem-estar. Preocupações legítimas com a manifestação de assimetrias e formas de opressão em relacionamentos aparentemente horizontais não justificam a adesão a um ideal de atomismo e indiferença, que é para onde aponta a exigência de "paternalismo zero".

Uma segunda forma de paternalismo envolve agentes que estão em posições

mostram como o debate sobre o argumento da angústia moral não está terminado. Líderes muçulmanos e de outras religiões, como o próprio papa Bergoglio, além de intelectuais laicos ligados a vertentes do chamado "multiculturalismo", manifestaram a opinião de que, por mais que os assassinatos fossem condenáveis, as charges "ofensivas" ao profeta Maomé tinham ido longe demais. 
diversas em uma determinada hierarquia, como patrão e empregados. Há uma diferença significativa entre a situação relatada antes, do amigo antitabagista, e outra, em que uma empresa decide confiscar e inutilizar os maços de cigarro de seus funcionários. Mesmo que a motivação seja genuinamente altruísta, há uma violação da esfera pactuada de exercício da autoridade, cuja delimitação é crucial para os trabalhadores. Além disso, há a impossibilidade de reciprocidade, que marca uma distinção crucial entre esta e a relação entre amigos.

Uma ordem diferente de questões se coloca a partir de outra relação assimétrica, aquela entre um agente dotado de conhecimentos específicos e seus clientes. O principal exemplo é o do médico, mas também é possível pensar em advogados, publicitários ou administradores de empresas, entre outros. Na relação com o paciente, o médico encarna um sistema perito, isto é, um dos "sistemas de excelência técnica ou expertise profissional que organizam grandes áreas dos ambientes material e social em que nós vivemos hoje" (Giddens, 1990, p. 27). É uma relação de confiança, uma vez que a assimetria de saberes torna implausível que o paciente seja capaz de avaliar a correção das prescrições do médico. Ao manipular as informações que fornece, com o objetivo de forçar o paciente a tomar as decisões "certas" sobre o tratamento, o médico manifesta menosprezo por sua capacidade cognitiva e nega a ele a possibilidade de ação autônoma. Até porque a avaliação de riscos e benefícios do profissional não é necessariamente a mesma que a do doente.

Mas a forma mais relevante de paternalismo, discutida pela literatura, é o paternalismo público, aquele patrocinado pelo Estado ${ }^{10}$. Na percepção liberal, o Estado deve garantir o usufruto das liberdades individuais pelos cidadãos e manter a neutralidade em relação às diferentes visões de mundo que eles abraçam. No entanto, muitas políticas públicas visam impedir decisões individuais erradas ou, ao menos, direcioná-las para o lado considerado correto - numa longa lista que inclui a obrigatoriedade do uso de cinto de segurança em automóveis (ou capacetes em motocicletas), planos previdenciários compulsórios ou a introdução de alertas nas embalagens de produtos danosos à saúde, como cigarros.

Para liberais extremados, como Robert Nozick (1974), são medidas que ferem a autonomia decisória individual. Os próprios propositores das medidas buscam, muitas vezes, argumentos não paternalistas para defendê-las - por exemplo, a economia nos gastos com saúde pública, com a redução de acidentes ou do câncer pulmonar. No caso da previdência compulsória, Elizabeth Anderson criou um engenhoso argumento para justificá-la com base não no paternalismo, mas no dever social de estender a todos os cidadãos as condições para uma vida digna (Anderson, 1999, p. 319). Embora o ponto

\footnotetext{
${ }^{10} \mathrm{Na}$ verdade, as igrejas também poderiam ser listadas entre as fontes de paternalismo público, mas em geral não o são. A ideia é que o pertencimento religioso é voluntário, o que afastaria boa parte dos problemas vinculados ao paternalismo estatal. No entanto, uma análise mais sensível aos processos de produção das preferências coloca em xeque o caráter voluntário da adesão às religiões.
} 
central de Anderson no artigo seja correto - criticar a ênfase dworkiniana na responsabilidade individual -, o pavor a qualquer vinculação com uma postura paternalista leva a manobras retóricas pouco aceitáveis. A imposição do direito à vida digna na velhice a pessoas que, por miopia (deflação do peso concedido a seu bem-estar futuro), fraqueza da vontade ou penúria (impossibilidade de arcar com despesas além das imediatas), não buscam sustentá-la na juventude possui, sim, um inegável componente paternalista.

Talvez seja mais razoável (e honesto) entender que as diferentes liberdades possuem significados diferentes e o cerceamento de algumas - como a liberdade de dirigir sem cinto de segurança - não leva à "infantilização" denunciada pelos antipaternalistas (Marneffe, 2006, p. 68) ${ }^{11}$. E, no caso da previdência, introduzir um componente de solidariedade social, que pode justificar, em determinados casos, a introdução de barreiras paternalistas contra déficits de racionalidade, como a miopia e a fraqueza da vontade.

Em sua controversa defesa de algumas formas de paternalismo público, Sunstein (2014) se debruça sobre a questão da "arquitetura da escolha". Sua opção é por formas de paternalismo suave (soft), que não retiram a possibilidade de decisão individual, mas salientam informações relevantes em detrimento de outras e reduzem ou ampliam custos das diferentes alternativas. Em sua abordagem anterior do problema, ele questionava as próprias preferências expressas pelos indivíduos, "produto da informação disponível, padrões de consumo vigentes, pressões ou normas sociais e regras governamentais", concluindo que "a interferência governamental sobre as escolhas ou desejos existentes pode ser justificada pelos problemas nas origens desses desejos" (Sunstein, 1997, p. 19). A opção pelo paternalismo suave é bem mais moderada e não questiona o grau de autonomia na formação das preferências expressas.

Um exemplo de paternalismo suave está na determinação de qual opção será considerada padrão, portanto beneficiada pela inércia que é própria de tantas tomadas de decisão. A redação original da lei 9.434 , de 1997, que regulamenta a doação de órgãos no Brasil, operava nesse sentido, indicando que, "salvo manifestação de vontade em contrário, [...] presume-se autorizada a doação de tecidos, órgãos ou partes do corpo humano, para finalidade de transplantes ou terapêutica post-mortem"12. O ônus da escolha passaria para os não doadores. Uma campanha de atemorização da população, baseada na ideia de que haveria um estímulo à negligência médica para favorecer o tráfico de órgãos, levou à alteração da lei, em 2001. O exemplo não é particularmente paternalista - a medida visava a incentivar um comportamento que beneficiaria a terceiros -, mas mostra como a alteração da opção-padrão pode gerar, por si só,

\footnotetext{
${ }^{11}$ A hierarquização das liberdades, aliás, é mobilizada, em polêmica contra os libertarianos, pelo próprio Ronald Dworkin (2005, p. 282).

${ }^{12}$ Disponível em: <http://www.planalto.gov.br/ccivil_03/leis/l9434.htm>. Acesso em: 16 jun. 2014.
} 
mudanças significativas nos resultados.

O argumento de Sunstein é que não há escolha sem que haja uma arquitetura própria. Algumas opções aparecem antes de outras, algumas informações obtêm mais destaque. Há uma série de mecanismos psicológicos que fazem com que esses elementos condicionem escolhas que não passam necessariamente por um crivo racional. A alternativa, assim, não é entre uma escolha inteiramente livre de constrangimentos e outra, direcionada. É entre duas escolhas direcionadas diferentemente. O paternalismo governamental suave é justificado, se visa a favorecer opções que contribuam para a saúde pública ou a proteção do meio ambiente, já que não limitaria a liberdade individual, ou, pelo menos, não mais do que ela estaria restrita em qualquer outra condição de escolha.

Dois exemplos, utilizados pelo próprio Sunstein, ajudam a entender a situação. Um é a exibição obrigatória de informações sobre o consumo de combustível nos veículos à venda, chamando a atenção dos potenciais compradores e estimulando que esse critério seja considerado nas suas decisões. Outro é a proposta (derrotada) do então prefeito de Nova York, Michael Bloomberg, de proibir a venda de refrigerantes em frascos superiores a 16 onças (um pouco menos de meio litro), como forma de combater a obesidade. Nos dois casos, a liberdade de escolha não é violada. Os consumidores podem comprar carros que gastam muito combustível, a despeito dos avisos governamentais. E, embora não pudessem comprar copos ou garrafas enormes, poderiam continuar tomando grandes quantidades de refrigerantes, bastando para isso comprar mais de uma unidade. São as formas de paternalismo que, na visão de Sunstein, não feririam a autonomia individual.

Os dois exemplos ilustram com clareza os limites da posição de Sunstein e, em particular, de sua compreensão da autonomia individual. No caso do consumo de combustível, a noção de que a busca por automóveis menos econômicos deve ser preservada como uma opção individual pode ser desafiada. De fato, uma interpretação restritiva do princípio milliano do dano definido não permite contestar a opção do consumidor, já que é improvável traçar o caminho que ligue o desperdício de um automóvel específico ao prejuízo a um indivíduo específico. No entanto, as questões da proteção do meio ambiente e da preservação dos recursos energéticos repercutem na vida de todos, o que justificaria uma intervenção para desestimular a compra ou mesmo banir veículos gastadores e poluentes. É algo que foge ao âmbito das discussões sobre paternalismo, pertencendo ao terreno do exercício da autonomia coletiva em questões de interesse comum.

A situação envolvendo o refrigerante é ainda mais relevante para a discussão. Embora o argumento da inevitabilidade da arquitetura da escolha seja um passo na direção correta, Sunstein não avança suficientemente. Afinal, por que uma campanha contra a obesidade é paternalista, mas a propaganda que fomenta o consumo de refrigerantes aparece como parte da ordem natural? Ao que parece, iniciativas que visam 
influenciar as pessoas em seu próprio benefício são vetadas, mas outras que pretendem induzi-las a adotar comportamentos que as prejudicam para favorecer a terceiros (a indústria do refrigerante, no caso) não seriam problemáticas. O subtexto, que está presente em muito da percepção liberal, ecoando assim suas origens em John Locke e Adam Smith, é que a autonomia se realiza nas relações de mercado. Elas aparecem como inerentemente justas, já que todos têm condição de perseguir seus próprios interesses, e por isso, como princípio, devemos assumir que regulá-las implica introduzir vieses danosos. Tal conclusão é desafiada, porém, quando é introduzido na narrativa o problema da formação das preferências e, junto com ele, o das relações sociais de dominação.

\section{A dominação em questão}

Levada ao excesso, como visto, a negação do paternalismo conduz a uma visão atomista da sociedade, negando os laços de afeição, solidariedade e preocupação mútua presentes no mundo social. Sem tal exagero, porém, o antipaternalismo toca em questões relevantes. O respeito à autonomia decisória dos indivíduos é uma condição de igualdade, necessária à efetivação de uma sociedade democrática. Muitas vezes, é invocado para proteger aqueles em condição mais frágil e para fazer que a expressão de seus interesses seja considerada: as mulheres, os mais jovens, os integrantes de culturas minoritárias, os menos escolarizados, os trabalhadores. De maneira geral, todos aqueles que possuem menor domínio das ferramentas discursivas legítimas e que, por isso, são estigmatizados como dotados de menor capacidade cognitiva.

Não se trata, portanto, de negar relevância ao problema do paternalismo, mas de indicar que, ao estabelecê-lo como "o" problema a ser enfrentado para garantir a agência autônoma, o pensamento liberal desloca a discussão de maneira a deixar de fora o principal. O obstáculo mais importante à ação autônoma e à formação autônoma de preferências não é o paternalismo, mas a dominação. Essa é a categoria que deve ser levada centralmente em conta, para a produção de uma reflexão crítica sobre o mundo social. Indivíduos e grupos têm dificuldade de formular e expressar autonomamente suas preferências quando estão sujeitos a relações de dominação.

O conceito de dominação liga a divisão desigual de vantagens à influência diferenciada que uns têm sobre as ações de outros. Em grande parte das discussões da teoria política contemporânea, a questão é tratada a partir da versão neorrepublicana, que anexou o conceito à sua tese da "liberdade como não dominação" (cf. Pettit, 1997; Lovett, 2010). Para os neorrepublicanos, há dominação quando alguém está em condições de interferir, "numa base arbitrária", sobre algumas escolhas que o outro poderia fazer (Pettit, 1997, p. 52). Há um ganho e um retrocesso nessa definição. A ênfase na possibilidade de interferir permite identificar a dominação mesmo em situações em que a vulnerabilidade do dominado à interferência não é aproveitada por quem está 
em condições de fazê-lo. Mas, por outro lado, a cláusula de arbitrariedade abre espaço para que um grande espectro de interferências seja legitimado. É possível lê-la aderindo à visão liberal do contrato, que transformaria em voluntárias (e portanto não arbitrárias) as mais diferentes relações assimétricas - no trabalho, no casamento, na política.

É mais produtiva a definição de Iris Marion Young, segundo a qual a dominação

consiste em condições institucionais que inibem ou previnem as pessoas de participar na determinação de suas ações ou das condições de suas ações. As pessoas vivem dentro de estruturas de dominação se outras pessoas ou grupos podem determinar, sem reciprocidade, as condições de sua ação, seja diretamente ou em virtude das consequências estruturais de suas ações (Young, 1990, p. 38).

Entre os ganhos da definição de Young, cumpre destacar a ênfase no caráter estrutural das relações de dominação. Para compreender o fenômeno da dominação em qualquer sociedade complexa, é crucial superar os modelos em que "A domina B", sendo A e B indivíduos singulares e sua relação marcada por um elevado grau de voluntarismo. Há uma distribuição de recursos e de possibilidades que determina o fluxo de vantagens e desvantagens entre grupos, de acordo com sua posição social, demarcada por instituições como mercado, família e Estado.

A limitação que as relações de dominação impõem à autonomia não é apenas externa, vinculada ao controle de recursos e à amplitude do cardápio de escolhas factíveis, mas também - e mesmo sobretudo - interna. Como fenômeno estrutural, a dominação se liga à imposição de representações do mundo e valores que favorecem sua própria reprodução. Uma versão particularmente forte dessa percepção se encontra na sociologia de Pierre Bourdieu. A característica central da dominação é o fato de que "o dominado tende a assumir a respeito de si mesmo o ponto de vista dominante" (Bourdieu, 1998, p. 130). Não se trataria, como na noção marxista de ideologia, de uma "falsa consciência", mas da "submissão dóxica" às estruturas de uma ordem social que produzem simultaneamente o mundo social objetivado nas práticas e nas instituições e as estruturas mentais subjetivas (Bourdieu, 1994, p. 126).

É possível questionar a narrativa bourdieuana, observando que a adesão dos dominados às representações dominantes é bem mais nuançada do que parece à primeira vista (Scott, 1985, 1990). Mesmo assim, é inegável que há uma pressão permanente para a acomodação com os pressupostos das instituições vigentes, algo que o próprio Scott destaca e que, na linguagem de Bourdieu, assume a forma da exigência de conformação às regras de cada campo social, destruindo as possibilidades de expressão e de ação próprias dos dominados (cf. Bourdieu, 1979, p. 538). De fato, a teoria de Bourdieu é útil sobretudo para colocar em xeque a dicotomia entre limitações externas e preferências internas, iluminando a profunda interconexão entre o mundo social e as estruturas mentais. 
Na teoria política contemporânea, muitas das principais contribuições para a discussão do problema vêm do feminismo. Ao analisar o problema da posição das mulheres em sociedades marcadas pela dominação masculina, o feminismo põe em questão as preferências expressas. Uma mulher pode expressar aceitação em relação à sua posição de inferioridade no casamento, aos padrões dominantes de beleza, ao uso de vestimentas impostas por líderes religiosos ou mesmo à mutilação genital. A expressão dessas preferências deve ser considerada sincera, em circunstâncias nas quais a dissidência é punida com a estigmatização? E, mesmo que o seja, deve ser aceita sem que se investiguem as condições em que as preferências foram produzidas e formuladas?

O que está em questão, no exemplo, é a dominação - e não o paternalismo -, pois são preferências induzidas que mantêm e reproduzem relações que garantem vantagens simbólicas e materiais aos homens, enquanto grupo. O que está em questão não é impedir que preferências sejam desconsideradas (por alguém que adota uma posição paternalista e indica alternativas que seriam superiores), e sim tematizar as condições de formulação das preferências, pelos diferentes indivíduos e grupos, mostrando como relações de dominação enviesam sistematicamente esse processo. Dito de outra forma, não é possível tratar da circulação das preferências sem analisar também a sua produção.

Em particular: (1) há o efeito da privação material, que reduz o horizonte de possibilidades e ambições; (2) há a dificuldade de acesso às ferramentas cognitivas e à informação necessárias para pensar a própria posição no mundo; (3) há a imposição de visões de mundo dos grupos que controlam os instrumentos de difusão das representações do mundo social; e (4) há os custos diferenciados para a adoção de determinadas preferências, de acordo com a posição estrutural dos sujeitos.

O ponto (1) recai na discussão sobre "preferências adaptativas" (Knight e Johnson, 1997), que a fábula da raposa e das uvas ilustra. Não se trata apenas de saber que eu não terei acesso a algo que eu quero, mas de deixar de querer aquilo a que eu não tenho acesso, seja por ação de mecanismos de redução da frustração, seja pelo estreitamento de horizontes gerado por condições de vida adversas. A privação material impõe a necessidade da própria subsistência como imperativo primordial e gera a impressão de que determinados espaços sociais estão vedados de antemão. Melhorias na situação levam à modificação das ambições (o que é captado pela ideia da espiral ascendente das expectativas, segundo a qual uma evolução nas condições de vida faz ampliar as exigências dos mais desfavorecidos) e, além disso, medidas específicas podem se contrapor à tendência. Por exemplo, um dos efeitos esperados de políticas afirmativas, como cotas em universidades, é precisamente ampliar o horizonte de ambições dos integrantes de grupos em posição subalterna, contrapondo-se à tendência à adaptação a um universo reduzido de possibilidades objetivas ${ }^{13}$.

13 Antes das políticas de cotas, financiamento e expansão do sistema universitário, o ensino superior 
O ponto (2) é uma condição de possibilidade da formação de preferências consequentes, uma vez que, sem um mínimo de informações adequadas, não é possível se posicionar em relação ao mundo. Mas não se trata apenas de "informação", no sentido factual, avançando para o ponto (3). As representações do mundo social carregam valores, critérios de apreciação, mecanismos explicativos. Famílias, escolas, igrejas e mídias estão entre os sistemas que disseminam tais representações, com diferentes graus de abrangência. O controle concentrado da capacidade de disseminação de tais visões do mundo está na raiz daquilo que Iris Marion Young chamava de "imperialismo cultural". A experiência e a cultura do grupo dominante são universalizadas e os dominados são, ao mesmo tempo e paradoxalmente, marcados por estereótipos e tornados invisíveis (Young, 1990, p. 58-59). São subtraídas ferramentas necessárias à tematização da própria experiência e, portanto, à produção de preferências condizentes com ela.

O ponto (4), por fim, ilustra que as pressões sociais não são uniformemente decididas, mas incidem diferentemente de acordo com a posição na estrutura social. Assim, por exemplo, dada a divisão sexual do trabalho e o peso simbólico do matrimônio, numa sociedade estruturada pela dominação masculina o custo da preferência por sair de um casamento insatisfatório ou mesmo violento costuma ser muito maior para as mulheres do que para os homens. É a "vulnerabilidade diferenciada" de que falava Susan Okin (1989). Por outro lado, a família, como rede de apoios e solidariedades, ainda que tingida por padrões de opressão interna, é mais crucial para mulheres negras e trabalhadoras do que para profissionais brancas, que podem esperar sucesso e independência no mercado de trabalho (Hooks, 2000, p. 38).

É necessário discutir o problema escapando das armadilhas tanto do objetivismo (as preferências reais são identificáveis por um observador externo) quanto do subjetivismo (as preferências reais são aquelas expressas pelos indivíduos). 0 objetivismo carrega um risco autoritário (presente, por exemplo, na noção de interesse objetivo na tradição marxista, com sua distinção arbitrária entre "classe em si" e "classe para si" e a identificação de uma consciência "verdadeira", oposta a outras, "falsas"). O subjetivismo pode conduzir ao conformismo, em que a adequação ao que está dado é presumida e falta atenção aos elementos de controle e de manipulação. A solução é uma "posição impossível", que exige a capacidade de questionar as preferências subjetivas sem postular a existência de preferências objetivas. Para tanto, as preferências devem ser investigadas não como pontos fixos, mas como processos - e é relevante entender se existem custos excessivos para a adoção de preferências alternativas, se há mesmo a possibilidade de considerá-las e se os sujeitos são capazes de refletir sobre si mesmos,

estava fora das expectativas das populações das periferias brasileiras. O protagonista da canção "Vida bandida", de Rappin' Hood (incluída no álbum Sujeito homem, de 2001), sonhava "ter estudo/colegial completo". Universidade, nem no sonho. É um exemplo das preferências adaptativas. 
suas escolhas e suas circunstâncias.

Ao mesmo tempo, é necessário evitar as ilusões paralelas do atomismo (os indivíduos deveriam ser capazes de produzir suas preferências no vácuo das pressões sociais) e do comunitarismo (a socialização é a fonte incontestável do sentido). É mais produtivo manter a relação entre indivíduo e comunidade como uma tensão que não se resolve, nem na teoria nem na prática social, exigindo permanente negociação.

As visões comunitaristas, como observado antes, dizem que não temos como ter preferências efetivas fora do horizonte dos valores normativos compartilhados. Mas há graus de distanciamento reflexivo, de capacidade de escrutínio crítico sobre as próprias pressões - e essa possibilidade deve ser valorizada como condição para uma agência mais autônoma. Até porque a "comunidade" também inclui relações de dominação no seu interior, quase sempre em prejuízo das mulheres e dos mais jovens.

Foi o que Susan Okin ressaltou, num texto que causou polêmica, desafiando a visão multiculturalista da proteção aos modos de vida minoritários em nome do ideal, liberal, da autonomia individual. Muito da polêmica deriva do fato de que a proteção às culturas minoritárias exige um relativo isolamento diante das influências externas, limitando a exposição a alternativas que fomentam a capacidade de leitura crítica da própria posição (Okin et al., 1999; cf. tb. Phillips, 2007). O caso das comunidades amish nos Estados Unidos, sempre lembrado nessa discussão, é um exemplo extremo.

Não é possível pensar num distanciamento completo em relação ao quadro de valores e visões de mundo que informam nossas decisões, como no ideal de uma "objetivação" emancipadora, a "socioanálise" que nos liberaria do nosso inconsciente social, apresentado por Pierre Bourdieu (cf. Bourdieu e Chartier, 2010; para uma crítica, Miguel, 2015). Mas é possível, sim, vislumbrar condições de ampliação da capacidade crítica, pela redução das vulnerabilidades e ampliação do acesso a informações e visões de mundo alternativas.

O que está em questão, porém, não é só, nem mesmo principalmente, a autonomia ou a capacidade de produção autônoma de preferências como um atributo de tal ou qual indivíduo. Para uma crítica consequente dos processos sociais de formação das preferências, é preciso focar nos mecanismos que induzem sistematicamente a opção por determinados tipos de preferência. Trata-se de dar atenção, novamente, à atuação dos aparelhos ideológicos (isto é, formas institucionalizadas de disseminação de valores e de visões de mundo). Dois exemplos são a publicidade comercial (que dissemina a preferência pelo consumo conspícuo, favorece um etos aquisitivo etc.) e a religião (que determina as fronteiras da norma e do desvio) ${ }^{14}$.

\footnotetext{
${ }^{14}$ Ganha relevância aqui a questão do controle da mídia. Os meios de comunicação de massa são os principais difusores das representações do mundo nas sociedades contemporâneas, com forte influência, portanto, sobre as mentalidades e a produção das preferências. A ausência de uma pluralidade de valores e perspectivas no discurso da mídia compromete o acesso à diversidade de "possíveis" que, segundo tento demonstrar neste artigo, é condição para a efetiva ação autônoma.
} 
Mais do que tal ou qual constrangimento individual, o problema é a capacidade diferenciada que os diversos grupos têm de influenciar essas estruturas. A capacidade de influenciar preferências alheias não é "inocente"; essa influência se faz em favor dos próprios interesses. Trata-se de algo crucial para a reprodução dos padrões sociais de dominação. Após indicar o controle dos meios de coerção física e dos meios de produção da riqueza como as bases do poder em qualquer sociedade, Piven e Cloward acrescentam que "essas fontes de poder são protegidas e ampliadas pelo uso desse poder não apenas para controlar as ações de homens e mulheres, mas também para controlar suas crenças" (Piven e Cloward, 1979, p. 1).

Publicidade comercial e religião servem, de novo, como exemplos. Anda bem desgastado o discurso crítico à "sociedade de consumo" e às formas de cooptação e acomodação que ela enseja. Mas continua sendo um discurso merecedor de atenção. A ideia de que o consumo é o caminho para a autorrealização, com o consequente insulamento na vida privada, contribui de forma crucial para a reprodução da ordem capitalista (Gorz, 1988). Já a religião, historicamente, se caracteriza como uma forma de controle das mulheres, que contribui de forma decisiva para reproduzir a dominação masculina, e uma forma de acomodação dos oprimidos, contribuindo para sua subserviência.

O problema, assim, é que alguns têm alto poder de influenciar as preferências alheias e outros estão apenas submetidos a essas influências, graças ao controle diferenciado sobre recursos materiais e simbólicos. Por isso, indicar o paternalismo como o principal adversário a ser enfrentado é formular o problema de uma maneira que impede a sua solução. O antipaternalismo tende a assumir as preferências expressas pelos indivíduos como não problemáticas, exceto quando há coerção aberta. No entanto, as condições para a produção razoavelmente autônoma das preferências são - como visto - bastante mais exigentes. Elas falham quando há, por exemplo, uma condição de privação material, a ausência de informação plural, um baixo desenvolvimento de ferramentas cognitivas ou custos materiais e/ou simbólicos elevados em caso de mudança nas preferências expressas. O debate na literatura feminista sobre o estatuto da adesão "espontânea" de mulheres a ditames sexistas de base religiosa, como o affaire du foulard francês ou mesmo a mutilação genital feminina (cf. Nussbaum, 1999, cap. 4), é revelador da complexidade da questão.

Um antipaternalismo consequente deve ser entendido como a busca pela ampliação das condições de produção autônoma de preferências individuais e também coletivas, não como aceitação acrítica da expressão atual delas. Mais importante do que isso, porém, é observar que a distinção paternalismo/antipaternalismo está longe de esgotar o problema. Não apenas as preferências são sempre socialmente produzidas, como o são em ambientes em que alguns grupos possuem maior capacidade de transmitir suas visões de mundo e de impor seus valores, em que existem padrões estruturados de silenciamento. Ou seja, a questão central não é o paternalismo, mas a 
dominação. Múltiplos mecanismos nas relações de dominação submetem a formação das preferências dos dominados a pressões e constrangimentos por parte dos dominantes. $E$ o que se efetiva não é uma relação paternal (que ocorreria pretensamente em favor do bem-estar do tutelado), mas a busca da redução dos custos da dominação.

A ideia de autonomia é central porque implica tanto a capacidade de que os indivíduos produzam, coletivamente, seus próprios interesses quanto de que renegociem suas identidades e pertencimentos de grupo. "Autonomia" não significa que o self paira acima e além das relações sociais que o constituem. Mas também não é uma ilusão, uma vez que não seríamos mais do que um produto do nosso pertencimento comunitário - o "quem sou eu?" descartando o "que objetivos eu escolho?", como no relato de Sandel (1998). Autonomia significa que, embora sejamos seres sociais, somos capazes de desenvolver competências que nos permitem avaliar criticamente as tradições e os valores que herdamos (Barclay, 2000). Entendida como um bem social, necessário à democracia, estabelece a necessidade de universalização dos recursos materiais, informacionais e cognitivos que permitem seu desenvolvimento.

\section{Conclusão}

É razoável ver nas relações paternalistas uma forma de dominação. Quem exerce o paternalismo nega ao outro a possibilidade da autodeterminação. Mas ele é uma expressão muito específica, que não compreende todo o amplo espectro das formas de dominação social. Como disse E. P. Thompson, o paternalismo envolve "implicações de calor humano e relações próximas que subentendem noções de valor. Confunde o real e o ideal" (Thompson, 1998, p. 32). O historiador se referia a um problema diferente, recusando a caracterização da relação entre a gentry e os trabalhadores pobres na Inglaterra do século XVIII como "paternalista", mas sua observação cabe aqui. Quando afastamos a presunção de que há, por parte de quem exerce a influência, uma preocupação genuína com o objeto da ação, os limites da abordagem centrada no paternalismo se evidenciam.

É mais útil construir o problema como sendo relativo aos obstáculos que a dominação apresenta à autonomia dos agentes - e aí o paternalismo entra como um caso - em vez do contrário. Para tanto, é necessário entender a formação das preferências não só, nem mesmo prioritariamente, no nível dos indivíduos, mas no nível da sociedade, isto é, levando em conta as estruturas (e que grupos as controlam). É possível voltar, aqui, aos exemplos da raposa com as uvas e de Ulisses amarrado no mastro, mobilizados por Jon Elster para ilustrar a inter-relação entre preferências e circunstâncias. A preocupação de Elster, já sabemos, é com a ação individual, com os problemas relacionados à mudança das preferências pessoais no tempo e com os mecanismos de produção de "pré-compromissos" e de restrições autoimpostas (Elster, 2009b). Mas, se pensarmos no mundo social de forma mais ampla, observamos que 
temos muitas raposas e poucos Ulisses. Para a maior parte das pessoas, coloca-se como imperativo reduzir suas ambições, adequar-se a um horizonte limitado de possibilidades e adaptar suas preferências diante de circunstâncias que elas não controlam. E alguns poucos têm a possibilidade de alterar as circunstâncias, não só as suas, mas as dos outros.

O que gera essa possibilidade é o controle diferenciado de recursos materiais e simbólicos, estabelecendo assimetrias na influência sobre mercados e Estado e no acesso às posições de autoridade e aos espaços de difusão das representações do mundo social. A desigualdade no acesso à autonomia individual e na participação na autonomia coletiva pode, assim, ser considerada a desigualdade política central, que condensa todas as outras.

Luis Felipe Miguel - Instituto de Ciência Política, Universidade de Brasília. E-mail: <luisfelipemiguel@gmail.com>.

\section{Referências bibliográficas}

ANDERSON, E. S. "What is the point of equality?". Ethics, Chicago, vol. 109, n², p. 287-337, mar. 1999.

BARCLAY, L. Autonomy and the social self. In: MACKENZIE, C.; StOLJAR, N. (eds.). Relational autonomy: feminist perspectives on autonomy, agency, and the social self. Oxford: Oxford University Press, 2000.

BIRoli, F. Autonomia e desigualdades de gênero: contribuições do feminismo para a crítica democrática. Rio de Janeiro: Editora da UFF, 2013.

Bourdieu, P. La distinction: critique sociale du jugement. Paris: Minuit, 1979. . Raisons pratiques: sur la théorie de l'action. Paris: Seuil, 1994. . La domination masculine. Paris: Seuil, 1998.

Bourdieu, P.; Chartier, R. Le sociologue et I'historien. Paris: Agone, Raisons d'Agir, 2010.

CONLY, S. Against autonomy: justifying coercive paternalism. Cambridge: Cambridge University Press, 2013.

DAHL, R. A. Democracy and its critics. New Haven: Yale University Press, 1989.

DAWkins, R. Deus, um delírio. São Paulo: Companhia das Letras, 2007 [2006].

Dworkin, R. Uma questão de princípio. São Paulo: Martins Fontes, 2005 [1985].

ElSTER, J. Sour grapes. Cambridge: Cambridge University Press, 1983.

. Ulises y las sirenas: estudios sobre racionalidad e irracionalidad. México: Fondo de Cultura Económica, 1989 [1979]. 
Le désintéressement: traité critique de I'homme économique, I. Paris: Seuil, 2009a. . Ulisses liberto: estudos sobre racionalidade, pré-compromisso e restrições. São Paulo: Editora Unesp, 2009b [2000].

Fineman, M. A. The autonomy myth: a theory of dependency. New York: The New Press, 2005.

GIDDENS, A. The consequences of modernity. Stanford: Stanford University Press, 1990.

GoRz, A. Métamorphoses du travail: quête du sens. Critique de la raison économique. Paris: Galilée, 1988.

HAYEK, F. A. O caminho da servidão. Rio de Janeiro: Instituto Liberal, 1990 [1944].

Hooks, B. Feminist theory: from margin to center. Cambridge (MA): South End Press, 2000 [1984].

KNIGHT, J.; JOHNSON, J. What sort of political equality does deliberative democracy require?. In:

Bohman, J.; ReHG, W. (eds.). Deliberative democracy: essays on reason and politics. Cambridge, MA: The MIT Press, 1997.

LOVETT, F. A general theory of domination and justice. Oxford: Oxford University Press, 2010.

Marneffe, P. "Avoiding paternalism". Philosophy \& Public Affairs, Princeton, vol. 34, n 1, p. 68-94, jan. 2006.

Miguel, L. F. Democracia e representação: territórios em disputa. São Paulo: Editora Unesp, 2014. jun. 2015. "Bourdieu e o pessimismo da razão". Tempo Social, São Paulo, vol. 27, n 1, p. 197-216,

MILL, J. S. Sobre a liberdade. Petrópolis: Vozes, 1991 [1859].

O governo representativo. São Paulo: Ibrasa, 1995 [1861].

Nozick, R. Anarchy, State, and utopia. New York: Basic Books, 1974.

Nussbaum, M. C. Sex and social justice. Oxford: Oxford University Press, 1999.

. "Perfectionist liberalism and political liberalism". Philosophy \& Public Affairs, Princeton, vol. 39, n' 1 , p. 3-45, jan. 2011.

OKIN, S, M. Justice, gender, and the family. New York: Basic Books, 1989.

OkIN, S, M., et al. Is multiculturalism bad for women?. Princeton: Princeton University Press, 1999.

ORTEGA, F. "O sujeito cerebral e o movimento da neurodiversidade". Mana, Rio de Janeiro, vol. 14, $n^{\circ} 2$, p. 477-509, out. 2008.

"Deficiência, autismo e neurodiversidade". Ciência \& Saúde Coletiva, Rio de Janeiro, vol. 14, $\mathrm{n}^{\circ} 1$, p. 67-77, jan. 2009.

PETTIT, P. Republicanism: a theory of freedom and government. Oxford: Oxford University Press, 1997.

Phillips, A. Multiculturalism without culture. Princeton: Princeton University Press, 2007.

Piven, F. F.; Cloward, R. A. Poor people's movements: why they succeed, how they fail. New York: 
Vintage, 1979 [1977].

RAWLS, J. A theory of justice. Cambridge, MA: Harvard University Press, 1971.

Rousseau, J.-J. Du contrat social. In: Rousseau, J.-J. Euvres complètes, v. III. Paris: Gallimard, 1964 [1757].

. Emílio ou da educação. Rio de Janeiro: Bertrand Brasil, 1992 [1762].

SANDEL, M. J. Liberalism and the limits of justice. $2^{\mathrm{a}}$ ed. Cambridge: Cambridge University Press, 1998.

Santos, W. G. Ordem burguesa e liberalismo político. São Paulo: Duas Cidades, 1978.

SARTRE, J.-P. L'enfance d'un chef. In: Le mur. Paris: Gallimard, 1972 [1939].

ScorT, J. C. Weapons of the weak: everyday forms of peasant resistance. New Haven: Yale University Press, 1985.

Press, 1990.

Domination and the arts of resistance: hidden transcripts. New Haven: Yale University

Sunstein, C. R. Free markets and social justice. Oxford: Oxford University Press, 1997.

2014.

Why nudge? The politics of libertarian paternalism. New Haven: Yale University Press,

TAINE, H. "Note sur l'acquisition du langage chez les enfants et dans l'espèce humaine". Revue Philosophique de la France et de l'Étranger, Paris, vol. 1, p. 5-23, 1876. Disponível em:

<http://fr.wikisource.org/wiki/De_l\%E2\%80\%99acquisition_du_langage_chez_les_enfants_et_dans _|\%E2\%80\%99esp\%C3\%A8ce_humaine>. Acesso em: 16 jun. 2014.

TAYLOR, C. A ética da autenticidade. São Paulo: É, 2011 [2010].

THOMPSON, E. P. Costumes em comum: estudos sobre a cultura popular tradicional. São Paulo: Companhia das Letras, 1998 [1991].

TSAI, G. "Rational persuasion as paternalism". Philosophy \& Public Affairs, Princeton, vol. 24, $\mathrm{n}^{\circ} 1, \mathrm{p}$. 78-112, jan. 2014.

VAN PARIJS, P. "Why surfers should be fed: the liberal case for an unconditional basic income". Philosophy and Public Affairs, Princeton, vol. 20, n² 2, p. 101-131, mar. 1991.

. "Basic income capitalism". Ethics, Chicago, vol. 102, n 3, p. 465-484, mai. 1992.

WALzer, M. "The communitarian critique of liberalism". Political Theory, Newbury Park, vol. 18, $\mathrm{n}^{\circ} 1$, p. 6-24, jan. 1990.

Young, I. M. Justice and the politics of difference. Princeton: Princeton University Press, 1990. 


\title{
Resumo
}

\section{Autonomia, paternalismo e dominação na formação das preferências}

A questão da formação das preferências é ignorada pela maior parte da ciência política. A política seria um espaço apenas de agregação de preferências prévias. A justificativa do pensamento liberal para recusar a crítica da produção das preferências é a ideia de que cada um é o melhor juiz das próprias preferências. Caso não aceitemos isso, estamos caindo no paternalismo, em que a autonomia do agente é ameaçada pela ideia de que um observador externo estará em condições de identificar suas "verdadeiras" preferências mesmo contra sua vontade expressa. Meu argumento aqui é de que a posição antipaternalista está correta, em princípio, mas desloca a discussão. O principal obstáculo à formação autônoma de preferências não é o paternalismo, mas a dominação. Indivíduos e grupos têm dificuldade de formular e expressar autonomamente suas preferências quando estão sujeitos a relações de dominação.

Palavras-chave: preferências; paternalismo; dominação; liberalismo; autonomia

\author{
Abstract \\ Autonomy, paternalism, and domination in preferences formation
}

Formation of preferences is a question largely ignored by political science. Politics is seen just as a space to aggregate prior preferences. Liberalism justifies the refusal of a critique of preferences production by the idea that each person is the best judge of their own preferences. If we do not accept this, we are falling into paternalism, in which the autonomy of the agent is threatened by the idea that an outside observer will be able to identify their "true" preferences even against her expressed will. My argument here is that the anti-paternalistic position is correct in principle but shifts the discussion. The main obstacle to autonomous preference formation is not paternalism, but domination. Individuals and groups have difficulties to formulate and express their autonomous preferences when they are subject to relations of domination.

Keywords: preferences; paternalism; domination; liberalism; autonomy

\section{Resumen}

Autonomía, paternalismo, y dominación en la formación de preferencias

La formación de las preferencias es una cuestión ignorada en gran parte de la ciencia política. La política es vista simplemente como un espacio para agregar preferencias anteriores. El liberalismo justifica el rechazo de una crítica de la producción de las preferencias por la idea de que cada persona es el mejor juez de sus propias preferencias. Si no aceptamos esto, estamos cayendo de nuevo en el paternalismo, en el que la autonomía del agente se ve amenazada por la idea de que un observador externo será capaz de identificar sus preferencias "verdaderas", incluso contra su voluntad expresa. Mi argumento es que la posición anti-paternalista es correcta en principio, pero cambia la discusión. El principal obstáculo para la formación de preferencias autónomas no es el paternalismo, sino la dominación. Los individuos y los grupos tienen dificultades para formular y expresar sus preferencias de manera autónoma cuando están sujetos a relaciones de dominación.

Palabras-clave: preferencias; paternalismo; dominación; liberalismo; autonomía

\section{Resumé}

Autonomie, paternalisme et domination dans la formation des préférences

La formation des préférences est une question largement ignorée par la science politique. La politique est perçue comme un espace pour agréger des préférences antérieures. Le libéralisme justifie le refus d'une critique de la production des préférences par l'idée que chaque personne est le 
meilleur juge de ses propres préférences. Si nous ne l'acceptons pas, nous tombons dans le paternalisme, où l'autonomie de l'agent est menacée par l'idée qu'un observateur extérieur sera en mesure d'identifier les « vraies » préférences, même contre sa volonté exprimée. Mon argument ici est que la position anti-paternaliste est correcte en principe, mais elle déplace la discussion. Le principal obstacle à la formation autonome des préférences n'est pas le paternalisme mais la domination. Les individus et les groupes éprouvent des difficultés à formuler et à exprimer des préférences autonomes quand ils sont soumis à des rapports de domination.

Mots-clés: préférences; paternalisme; domination; libéralisme; autonomie

Artigo submetido à publicação em setembro de 2014.

Versão final aprovada em junho de 2015. 